\title{
GARANTIAS FUNDAMENTAIS DA PESSOA IDOSA: UMA REVOLUÇÃO POR DIREITOS RUMO À INCLUSÃO ${ }^{1}$
}

\author{
FUNDAMENTAL GUARANTEES OF THE OLDER PERSON: A REVOLUTION \\ FOR RIGHTS TOWARDS INCLUSION
}

\author{
Rogério Piccino Braga² \\ Flávia Piva Almeida Leite ${ }^{3}$ \\ Claudio José Amaral Bahia4
}

\begin{abstract}
Resumo
A consagração dos direitos fundamentais de minorias vulneráveis no Brasil, encontra justificativa não somente nos casos de compensação dos atos violadores praticados por nossos predecessores. É imprescindível a identificação de mecanismos de efetivação da igualdade, da liberdade e da dignidade do ser humano, independentemente de suas condições e opções, como no caso da pessoa idosa. Almeja-se com o trabalho demonstrar que as teorias explicativas do contrato social não previram uma sociedade como as atuais, mas sim uma sociedade única. Por essa razão, situações sociais hoje tidas como excludentes encontram na incompletude contratualista a falta de eficácia de direitos essenciais, ante os ultrapassados mecanismos de inclusão. Como se verá, a pessoa idosa não possui meios aptos à construção de identidade e, consequentemente, não vislumbra caminhos de dignidade perante o Estado, em que pese o extenso rol legislativo a tratar do tema.
\end{abstract}

Palavras-chave: Direitos fundamentais; pessoa idosa; identidade; dignidade humana.

Artigo submetido em 20/04/2017, pareceres de análise em 24/10/2017 e 13/12/2017, aprovação comunicada em 14/12/2017.

2 Doutorando e Mestre em Direito Constitucional pelo Centro Universitário de Bauru. Pós-graduado (especialização) em Direito Administrativo Municipal. Membro efetivo da Comissão Especial estadual de Ensino Jurídico da OAB/SP. Professor da Universidade Estadual do Norte do Paraná - UENP Jacarezinho/PR e UNOPAR/Bandeirantes. E-mail: <rogeriobraga@adv.oabsp.org.br>.

3 Doutora em Direito pela PUC/SP, Mestre em Direito pelo Centro Universitário de Bauru - ITE. Pósgraduada em Gerente de Cidades pela FAAP/SP. Professora Doutora da UNESP/FAAC/Bauru. Membro efetivo da Comissão de Logística, Infraestrutra e Desenvolvimento Sustentável e da Comissão do Acadêmico da OAB/SP. Avaliadora do CONPEDI. Pesquisadora. E-mail: $<$ flavialeite@faac.unesp.br>.

4 Doutor em Direito do Estado - PUC-SP. Mestre em Direito - ITE-Bauru. Professor do Programa de Mestrado do Centro Universitário de Bauru, mantido pela Instituição Toledo de Ensino - ITE. Email: < claudio_amaralbahia@hotmail.com >. 


\section{Abstract}

The consecration of the fundamental rights of vulnerable minorities in Brazil finds justification not only in cases of compensation for the violating acts practiced by our predecessors. It is essential to identify mechanisms for the realization of equality, freedom and dignity of the human being, regardless of their conditions and options, as in the case of the elderly person. The aim is to demonstrate that the explanatory theories of the social contract did not predict a society like the present one, but rather a unique society. For this reason, social situations today considered as excluding are in the incompleteness contractualist the lack of effectiveness of essential rights, before the outdated mechanisms of inclusion. As will be seen, the elderly person does not have the means to build identity and, consequently, does not envisage paths of dignity vis-à-vis the State, despite the extensive legislative role to deal with the subject.

Keywords: Fundamental rights; elderly; identity; human dignity.

Sumário: 1. Introdução. 2. A conformação normativa da proteção ao idoso no constitucionalismo brasileiro. 3. Desdobramentos conceituais acerca da legislação pátria sobre o idoso. 4. Os direitos da pessoa idosa como revolução por direitos e mecanismos de efetivação. 5. Conclusão. 6. Referências.

\section{$1 \quad$ INTRODUÇÃO}

O envelhecimento não é um fenômeno novo. Afinal, pela lógica natural da existência, os homens nascem, crescem, amadurecem, vivem e morrem. "Entretanto, essas fases da vida não eram, até a consolidação do modelo capitalista, objeto de saberes. Sobre a velhice não incidia nenhum valor, nenhum discurso, nenhum saber, nenhuma preocupação. Não era tema de relevância”.(RAMOS, 2014, p. 23).

A partir do século XIX, na medida em que o processo de industrialização avança, há a exigência de mão de obra mais qualificada, a qual requeria tempo e gastos para sua preparação. Dentro desse contexto, passa a ser conveniente que os trabalhadores também vivessem mais para recompensar os recursos gastos com a sua capacitação. Aliado a esse fator, em virtude do aumento da expectativa de vida, reflexo do desenvolvimento e progresso das sociedades, o idoso passa a usufruir de melhores condições psicológicas e físicas. Assim, como resultado dessa sociedade cada vez mais complexa, que exigia uma nova postura diante da existência, especialmente de sua duração como condição essencial para a própria sobrevivência do sistema em fase de afirmação, "a velhice passou a se apresentar 
como fenômeno não somente biológico, mas fundamentalmente social.". (RAMOS, 2014, p. 23).

A análise do envelhecimento não se tornou uma questão social relevante apenas pela quantidade de idosos cada vez maior em nossas sociedades ${ }^{5}$, mas, especialmente, pelo motivo dessas pessoas e demais grupos vulneráveis, tais como pessoas com deficiência, crianças e adolescentes dentre outros e, demais grupos sociais a eles solidários terem se mobilizado no sentido de exigir que direitos essenciais Ihes fossem reconhecidos.

A preocupação em assegurar os direitos das pessoas idosas ${ }^{6}$, no âmbito internacional e internamente, deu-se recentemente. Cabe esclarecer que, diferentemente de outros grupos vulneráveis, como o das pessoas com deficiência, o grupo de idosos não possui ainda um instrumento jurídico internacional, de caráter vinculante, para a defesa dos seus direitos humanos. ${ }^{7}$

No Brasil, a Constituição Federal de 1988 inaugura uma nova fisionomia ao Estado brasileiro, vez que não somente o consagrou democrático, mas também ressaltou o seu caráter essencialmente social, ao fundá-los em valores como a dignidade humana e cidadania, que irradiarão sobre todo o ordenamento. Esse novo modelo de Estado tem a tarefa fundamental de superar as desigualdades, não apenas econômicas e sociais, mas também as desigualdades ocasionadas em razão de raça, cor, sexo, condições físicas e de idade. (LEITE, 2012, p. 52 e 53).

5 Conforme podemos constatar no capitulo 1, do Envelhecimento global: triunfo ou desafio, no tópico a revolução demográfica que: "em todo o mundo, a proporção de pessoas com 60 anos ou mais está crescendo mais rapidamente que a de qualquer outra faixa etária. Entre 1970 e 2025, espera-se um crescimento de $223 \%$, ou em torno de 694 milhões, no número de pessoas mais velhas. Em 2025, existirá um total de aproximadamente 1,2 bilhões de pessoas com mais de 60 anos. Até 2050 haverá dois bilhões, sendo $80 \%$ nos países em desenvolvimento." Envelhecimento ativo: uma política de saúde / World Health Organization; tradução Suzana Gontijo. - Brasília: Organização Pan-Americana da Saúde, 2005. Disponível em endereço eletrônico: <http://bvsms.saude.gov.br/bvs/publicacoes/envelhecimento_ativo.pdf>. Acesso em: 10 jul. 2014.

E no Brasil, segundo dados da Pesquisa de Amostra por Domicílio, referente ao ano de 2011, divulgado em 2012, as pessoas com mais de 60 anos já são mais de 23,5 milhões. (BRASIL. Síntese de indicadores sociais. Uma análise das condições de vida da população. Rio de Janeiro: IBGE, 2012, p. 40 e 41)

6 Inúmeros termos e expressões são utilizados para designar quem são essas pessoas, marcados muitas vezes pela impropriedade e, outras tantas dando uma conotação negativa: "pessoa da terceira idade", "pessoa da melhor idade", "velhos", "pessoa de meia-idade", "melhor idade", "idade avançada", "pessoa idosa", entre outras. A Constituição Federal de 1988 utilizou em seu artigo 230, a expressão cunhada pela Organização Mundial de Saúde, em 1957, pessoa idosa. Diante disso, a Lei $n^{\circ} 10.741 / 03$ foi impulsionada adotar parte dessa expressão: idoso.

7 A Convenção sobre os Direitos das Pessoas com Deficiência e seu Protocolo Facultativo promulgada pela Organização das Nações Unidas em Nova Iorque em 2007. O Brasil, em 30 de março de 2007, assina essa Convenção e seu Protocolo Facultativo e, em julho de 2008 edita o Decreto-legislativo 186, que aprova o texto dessa Convenção e de seu protocolo facultativo. 


\section{A CONFORMAÇÃO NORMATIVA DA PROTEÇÃO AO IDOSO NO CONSTITUCIONALISMO BRASILEIRO}

Ao tratar dessas desigualdades, a Constituição inseriu, de forma inédita, a proteção constitucional às pessoas idosas. Assegurou de forma direta o amparo à velhice em seus artigos 229 e 230.

No plano infraconstitucional, foi promulgada a Lei $n^{\circ} 8.842 / 1994$ que dispõe sobre a Política Nacional do Idoso, com objetivo de assegurar os direitos sociais ao idoso, criando condições para promover sua autonomia, participação efetiva e integração na sociedade. Na sequência, é instituído o Decreto $n^{\circ} 4.227 / 2002$, que cria o Conselho Nacional dos Direitos dos Idosos, órgão vinculado ao Ministério da Justiça, com competência para supervisionar e avaliar a Política Nacional do Idoso, entre outras funções relacionadas à matéria. E, após dez anos da edição da lei conformadora da política nacional do idoso, em janeiro de 2004, entra em vigor a Lei $n^{\circ} 10.741 / 2003$, denominada Estatuto do Idoso, estabelecendo regras de direitos para proteção às pessoas com idade igual ou superior a 60 (sessenta) anos.

Trata-se de uma legislação moderna, na mesma linha do Estatuto da Criança e do Adolescente e do Código do Consumidor. É um verdadeiro microssistema jurídico, regulamentando todas as questões que envolvem a pessoa idosa, tanto no aspecto material, quanto processual. (FREITAS JÚNIOR, 2011, p. 3). O Estatuto do Idoso está estruturado em sete Títulos, a saber: Título I - Das Disposições Preliminares; Título II - Dos Direitos Fundamentais, este composto de dez Capítulos; Título III - Das Medidas de Proteção, subdividido em dois Capítulos; Título IV - Da política de atendimento ao idoso, com seis Capítulos; Título V - Do acesso à Justiça, disciplinado em três Capítulos; Título VI - Dos Crimes, com dois Capítulos; e Título VII - Das Disposições Finais e transitórias, enfeixando 118 artigos.

Cabe esclarecer que referido diploma incorporou e reafirmou em seu texto, a doutrina da proteção integral, antes já utilizada no Estatuto da Criança e do Adolescente. Encontrar-se-á ao longo do texto legal dispositivos que suprirão as deficiências sofridas pelos idosos no âmbito político e social. Enfim, a Lei 10.743/03 vem para consolidar a matéria jurídica relativa aos direitos e garantias do cidadão idoso. Afinal, o Brasil não é mais um país de jovens, mas um país em acelerado 
processo de envelhecimento. Esse perfil populacional exigirá do Estado e de toda sociedade ações efetivas para garantia dos direitos fundamentais das pessoas envelhecidas. (RAMOS, 2014, p. 159).

\section{DESDOBRAMENTOS CONCEITUAIS ACERCA DA LEGISLAÇÃO PÁTRIA SOBRE O IDOSO}

Mas que são as pessoas idosas? Para os efeitos dessa Lei, considera-se pessoa idosa, segundo o artigo $1^{\circ}$, às pessoas com idade igual ou superior a 60 (sessenta) anos.

O envelhecimento deveria ter sido considerado pelo legislador como um processo tipicamente individual, existencial e subjetivo, afinal, cada existência humana é única, cada ser humano envelhece de maneira particular. Haveria necessidade de levar em consideração que cada indivíduo tem um tempo próprio para se sentir velho. Não há velhice e sim velhices. (BRAGA, 2011, p. 3).

Portanto, para desenvolver um conceito preciso sobre a velhice seria necessário considerar inúmeros fatores, uma vez que a velhice é um fenômeno complexo. A condição econômica dessas pessoas, seu grau de instrução, qual o tipo de alimento ingerido por elas, e como são suas relações familiares, dentre outros fatores. Nesse sentido, Paulo Roberto Barbosa Ramos (2014, p. 24), com base nas lições de Norberto Bobbio, Leonard Hayflick e Elida Séguin, afirma que para melhor compreensão do conceito de velhice, é necessário compreendê-la na perspectiva cronológica ou censitária, burocrática, fisiológica e psicológica ou subjetiva. A cronológica é aquela meramente formal. Parte de um patamar que, em sendo alcançado, identifica a quem o alcançou como velho.

A velhice burocrática corresponde àquela idade que, em sendo alcançada, a pessoa terá direito a uma aposentadoria. A fisiológica pode ser identificada como a fragilização da pessoa em virtude do passar dos anos; aquela que diz respeito ao enfraquecimento do organismo. Já a subjetiva é a mais complexa, já que não dispõe de parâmetros. Depende de cada pessoa. Acrescenta também, a velhice excluída (aquela personificada por aqueles velhos que sobrevivem nos meios rurais, suburbanos ou após as migrações), a pseudo velhice (por pessoas de 40 anos ou 
menos, desempregadas) e a precoce (pessoas que, em razão de condições altamente adversas de existência, envelhecem muito cedo).

Todavia, o conceito eleito pelo legislador foi o critério cronológico para definir quem é considerado idoso para os efeitos da presente lei. Sendo o idoso a pessoa como idade igual ou superior a 60 anos de idade, homem ou mulher, nacional ou estrangeiro, urbano ou rural, trabalhador da iniciativa privada ou do serviço público, livre ou recluso, exercendo atividades ou aposentado, incluindo o pensionista e qualquer que seja a sua condição social. (MARTINEZ, 2005, p. 20). Porém, na prática, a maioria dos benefícios tem início aos 65 anos. Essa indefinição traz uma série de prejuízos em áreas importantes, cabendo destacar o direito à gratuidade no transporte coletivo, que exige a idade mínima de 65 (sessenta e cinco) anos, segundo dispõe o artigo 230, $\S 2^{\circ}$ da CF/88 e artigo 39, caput do Estatuto. Esta é também a idade exigida para obter prioridade na tramitação de processos judiciais, de acordo com a Lei 10.173 , de 09 de janeiro de $2001^{8}$. E também o do benefício da prestação continuada nos termos do artigo 34, caput da Lei de Organização da Assistência Social - LOAS.

De qualquer modo, não podemos deixar de destacar que, o Estatuto reconheceu o acesso das pessoas com 60 (sessenta) anos ou mais o pleno gozo de seus direitos, bem como a uma efetiva inclusão nos diversos segmentos da comunidade e o bem-estar delas, garantindo o respeito e a preservação de sua dignidade. Já em seu artigo $2^{\circ}$, o Estatuto assegurou ao idoso todos os direitos fundamentais inerentes à pessoa humana ${ }^{9}$, sem prejuízo da proteção integral, assegurando-se por lei ou por outros meios, todas as oportunidades e facilidades, para preservação de sua saúde física e mental e seu aperfeiçoamento moral, intelectual, espiritual e social, em condições de liberdade e dignidade. Em seu Título V - do Acesso à Justiça, a Lei assegurou em seus artigos 69 a 71, direito e garantias processuais aos idosos. Notadamente em seu artigo 70, determinou que o Poder Público poderá criar varas especializadas e exclusivas do idoso.

8 BRASIL, Lei n. ${ }^{0} 10.173$, de 09 de janeiro de 2011. Dispõe sobre o Estatuto do Idoso e dá outras providências. Diário Oficial União, 03 out 2001, p. 1.

9 "Art. 2ㅇ $\mathrm{O}$ idoso goza de todos os direitos fundamentais inerentes à pessoa humana, sem prejuízo da proteção integral de que trata esta Lei, assegurando-se-Ihe, por lei ou por outros meios, todas as oportunidades e facilidades, para preservação de sua saúde física e mental e seu aperfeiçoamento moral, intelectual, espiritual e social, em condições de liberdade e dignidade." 
Embora haja esta faculdade do Poder Público - leia-se mediante alteração da lei que organiza o serviço judiciário no Estado (art.125, da CF) por iniciativa do Tribunal de Justiça respectivo - ainda são raras as Varas especializadas e exclusivas do idoso e citamos como exemplo a Vara Especial Cível e Criminal de Belém. Se vierem a ser instaladas, estas Varas deverão estar aparelhadas suficientemente para atender à demanda para as quais concebidas, com boa estrutura de pessoal (assistente social, psicólogo etc.), eliminação de barreiras físicas e garantia de plena acessibilidade (rampas, banheiros com barras de apoio etc.), além de fácil acesso por meio de uma ampla rede de transporte público.

Não se pode esquecer que o art.80 estabelece como competência absoluta para conhecer das ações previstas no estatuto o foro do domicílio do idoso, que terá preferência sobre qualquer outra - até mesmo especializada, como pode acontecer em São Paulo com os foros regionais -, salvo as competências da Justiça Federal e a competência originária dos Tribunais Superiores (art.102 e seguintes da CF/88).

Notadamente em seu artigo 71, assegurou a prioridade na tramitação dos processos e procedimentos e na execução dos atos e diligências judiciais em que figure como parte ou interveniente pessoa com idade igual ou superior a 60 (sessenta) anos, em qualquer instância.

Esta preferência na tramitação vem expressamente prevista no art.1.211 A, do CPC. No caso do idoso, há preferência para o que está estabelecido no estatuto, porque é lei especial, posterior e que disciplinou totalmente a matéria.

Vale lembrar que a EC n.62/09 atribuiu a preferência do idoso no recebimento de precatórios de natureza alimentar, observado teto (art.100, par. $2^{\circ}$ da CF). A PEC 176/12 propõe incluir parágrafo ao art.100 da CF retirando idosos, pessoas com doenças graves ou incapacitantes da ordem de precatórios.

Basta que uma das partes seja idosa para se aplicar a preferência, em razão da clareza do dispositivo:

Ementa: Agravo de Instrumento Processual Civil Benefício da Assistência Judiciária e Prioridade do Idoso Indeferimento pelo Magistrado "a quo" Recurso manejado pelos autores Provimento parcial de rigor. 1. Providências processuais do art. 527 do CPC desnecessárias ante os documentos dos autos. Feito apto para pronto julgamento. 2. Da Prioridade do Idoso Benefício que deve ser reconhecido e outorgado Muito embora apenas parte dos autores-agravantes seja maior de 60 anos, o benefício se estende a todos os coautores Inteligência do artigo 71 da Lei Federal $n^{\circ}$ 10.741 /03 (Estatuto do Idoso) é por demais claro ao consignar que a 
prioridade na tramitação dos processos e procedimentos se aplica tão somente naqueles processos "em que figure como parte ou interveniente pessoa com idade igual ou superior a 60 (sessenta) anos". 3. De outra parte, o benefício da Assistência Judiciária não é cabível porque os autores percebem vencimentos médios superiores a $\mathrm{R} \$ 3.000,00 \mathrm{e}$, portanto, acima do rendimento médio do trabalhador nacional da ordem de $R \$ 1.500,00$. Decisão reformada em parte - Recurso provido em parte (TJ/SP Al 0043762-18.2013.8.26.0000). No mesmo sentido: TJ/SP Al 025308245.2012.8.26.0000, TJ/SP Al 2099276-82.2014.8.26.0000, TJ/RS Al 70045840618.

O § 1o deste mesmo artigo, determina que o interessado na obtenção da prioridade a que alude este artigo, fazendo prova de sua idade, requererá o benefício à autoridade judiciária competente para decidir o feito, que determinará as providências a serem cumpridas, anotando-se essa circunstância em local visível nos autos do processo. Cabe esclarecer que esse dispositivo é autoexplicativo sobre como formular o pedido, embora em alguns tribunais haja ato administrativo disciplinando com maiores detalhes este procedimento (p.ex. Resolução n.11/2003, do STJ).

Em seu § 2ㅇ A prioridade, dispõe que não cessará com a morte do beneficiado, estendendo-se em favor do cônjuge supérstite, companheiro ou companheira, com união estável, maior de 60 (sessenta) anos. Assim, exige-se para a manutenção da prioridade, que o cônjuge supérstite, companheiro ou companheira esteja em união estável e tenha 60 anos ou mais, não bastando simples namoro ou pouco tempo de convivência em comum. Aqui adotou-se a regra do art.1.723 do Código Civil que reconhece as uniões estáveis como entidade familiar.

Em seu $\S 3^{\circ}$, assegurou que a prioridade se estende aos processos e procedimentos na Administração Pública, empresas prestadoras de serviços públicos e instituições financeiras, ao atendimento preferencial junto à Defensoria Pública da União, dos Estados e do Distrito Federal em relação aos Serviços de Assistência Judiciária.

A prioridade processual e procedimental incide nos processos e procedimentos administrativos junto à administração direta (União, Estados, Distrito Federal e Municípios) e indireta (autarquias, fundações públicas, empresas públicas, sociedades de economia mista), aos órgãos públicos em geral, como o Poder Legislativo, Poder Judiciário, Ministério Público, Delegacias de Polícia, Procuradorias do Estado, da União, dos Municípios, especialmente aqueles órgãos ou instituições destinados a prestação de serviços de assistência judiciária gratuita, como é o caso 
das Defensorias Públicas estaduais, do Distrito Federal e da União e as Faculdades de Direito Públicas que prestem tais serviços. A prioridade também se estende às empresas prestadoras de serviços públicos - p.ex. de fornecimento de água, luz etc. - e concessionárias - p.ex. de transporte coletivo - delegatárias (p.ex. cartórios extrajudiciais em geral, como de protesto, registro civil etc.).

Cabe esclarecer que as instituições financeiras foram expressamente incluídas no dispositivo e esta prioridade também é tratada na lei nacional $\mathrm{n}$. 10.048/00, com a redação dada pelo art. 114 deste estatuto, que reduziu a idade para 60 anos.

E finalmente, em seu $\S 4$ 을 determinou que para o atendimento prioritário será garantido ao idoso o fácil acesso aos assentos e caixas, identificados com a destinação a idosos em local visível e caracteres legíveis. Portanto, esse artigo vem assegurar todos os direitos e garantias fundamentais inerentes à pessoa humana. ${ }^{10}$ Mas o que são direitos fundamentais?

Direitos essenciais e positivados no âmbito das Constituições democráticas a consagrar a proteção da dignidade humana, dotados de características que os individualizam ante a constante construção e reconstrução de sua natureza jurídica. Um conceito simples, porém, tradutor de elementos que identificam, no rol das Constituições dos séculos $\mathrm{XX}$ e $\mathrm{XXI}$, os chamados direitos fundamentais. Por encontram-se, como dito, em um rol enunciativo, por outras, localizados no texto constitucional, ainda que não assim designados, conforme prescreve o $\S 2^{\circ}$ do art. $5^{\circ}$ da Constituição da República Federativa do Brasil ${ }^{11}$.

10 Os doutrinadores constitucionalistas utilizam inúmeras expressões para nomear os direitos essenciais à pessoa humana, tais como: direitos do homem, direitos naturais, direitos individuais, liberdades públicas, direitos subjetivos públicos, direitos humanos e direitos fundamentais. Segundo nos ensina José Afonso da Silva em sua obra Curso de direito constitucional positivo, p. 175, a ampliação e transformação dos direitos fundamentais do homem são as grandes responsáveis pela dificuldade de obter-se um conceito sintético e preciso a respeito desta espécie. Até porque, segundo Alexandre de Moraes, em Direitos humanos fundamentais, p. 1, os direitos humanos fundamentais, em sua concepção atualmente conhecida, surgiram como produto da fusão de várias fontes, desde a conjugação de pensamentos filosófico-jurídicos até as ideias surgidas com o cristianismo e com o direito natural. A expressão direitos fundamentais, segundo a maior parte da moderna doutrina constitucional, são aqueles reconhecidos e vinculados à esfera do Direito Constitucional de determinado Estado, enquanto que os direitos humanos estão firmados pelas posições jurídicas de âmbito internacional. Como nosso legislador constituinte de 1988 utilizou no texto de nossa Constituição de 1988, em seu Título II "Dos Direitos e Garantias Fundamentais", utilizaremos a terminologia direitos fundamentais por entender ser esta expressão mais adequada no sentido de abranger as várias dimensões/gerações dos direitos que iremos estudar tanto na Constituição Federal como no Estatuto do Idoso.

11 "Art. $5^{\circ}(\ldots)$. $\S 2^{\circ}$ Os direitos e garantias expressos nesta Constituição não excluem outros decorrentes do regime e dos princípios por ela adotados, ou dos tratados internacionais em que a República Federativa do Brasil seja parte." 
Em que pese a situação atual de vigência dos direitos fundamentais na Carta constitucional brasileira de 1988 , há de se consignar a preocupação tardia do ser humano quanto à proteção dos direitos fundamentais. A seguir, os conceitos de direitos fundamentais e de direitos humanos serão separados no texto pelo âmbito de positivação e, unidos, porém, pela semelhança no que se refere à proteção da dignidade humana - sem rechaçar, entretanto, o campo da divergência terminológica que surge ao se falar em uma de suas características comuns, a universalidade. A pesar sobre tal característica, o maior campo de crítica. Fábio Konder Comparato pondera acerca dessa preocupação tardia do próprio ser humano, em imprimir efetividade à proteção internacional dos direitos humanos aqueles positivados nas Constituições de cada Estado Democrático:

Foi durante o período axial da História, como se acaba de assinalar, que despontou a ideia de uma igualdade essencial entre todos os homens. Mas foram necessários vinte e cinco séculos para que a primeira organização internacional a englobar a quase totalidade dos povos da Terra proclamasse, na abertura de uma Declaração Universal de Direitos Humanos, que "todos os homens nascem livres e iguais em dignidade e direitos. (COMPARATO, 2015, p. 24).

Se por um lado vislumbra-se a afirmação histórica dos direitos humanos com início no contexto inglês de positivação, traduzidos nos primeiros ensaios de proteção ${ }^{12}$ da Magna Charta Libertatum (Carta das liberdades) ou Concordiam inter regem Johannen at barones pro concessione libertatum ecclesiae et regni angliae ${ }^{13}$, passando pela Petition of Rights, instituída em 07 de julho de 1628 a fim de estender, então, as liberdades previstas na Carta de 1215, aos súditos (devido processo legal, dentre outros), em seguida, pelo Habeas Corpus Act, ou Lei do habeas corpus, consagrando o instrumento como mecanismo processual a fim de proteger a liberdade dos indivíduos, evitando, assim, prisões arbitrárias, até a Declaração de Direitos - Bill of rights - em 1689, que decretou o final da monarquia - ainda assim o mundo não vislumbrava uma preocupação global com a proteção dos direitos humanos (fundamentais).

12 Em que pese a não extensão de sua eficácia dos direitos ali previstos, aos súditos, quando da conformação da Magna Charta Libertam de 1215, por João Sem-Terra - uma imposição ante os conflitos com a Igreja e com os Barões da época.

13 Concordata ou concórdia entre o rei João Sem-Terra e os Barões da época, a fim de estabelecer liberdades para a Igreja e ao reino inglês. 
Da mesma forma se deu com a afirmação histórica dos direitos humanos no cenário norte-americano, a saber, com a Declaração de direitos do bom povo da Virgínia (1776), uma das treze colônias inglesas instaladas em solo estadunidense, com a Declaração de Independência dos Estados Unidos da América no mesmo ano e com a promulgação da Constituição dos Estados Unidos da América em 1787. Esse era o móvel da luta estadunidense pela afirmação dos direitos humanos: a independência dos Estados Unidos da América, e não a preocupação com a proteção global dos direitos humanos, tendo como titulares todos os seres humanos.

Somente no contexto francês é que a universalidade de tais direitos ganhou destaque, com a proclamação da Declaração dos Direitos do Homem e do cidadão, em 26 de agosto de 1789, no cenário da Revolução Francesa - um legado para o mundo todo no que concerne à defesa das liberdades essenciais do ser humano: liberdade, igualdade e fraternidade, como fundamentos e valores defendidos pelo então revolucionários. Nesse sentido, ressalta Gustavo Zagrebelsky:

Em el espíritu de la Revolución francesa, la proclamación de los derechos
servía para fundamentar uma nueva concepción del poder estatal,
determinando sus condiciones de legitimidade sobre la base de uma
orientación liberal. La Declaración no era propriamente derecho positivo,
sino um "reconocimiento" de las "verdades" de uma filosofia política,
presentada como el espíritu común de toda uma época, que pedia ser
llevada del campo de la teoría al de la práctica. El objetivo que se perseguía
era la demolición de las estructuras del Ancien Régime y la instauración del
reino de la libertad y la igualdad jurídica em uma sociedade que aún no
conocía ni la uma ni la outra y que sólo habría podido conocerlas a través
de uma profunda reforma de la legislación civil, penal y administrativa.
(ZAGREBELSKY, 2011, p. 52).

As características desses direitos são bem definidas nas lições de Luigi Ferrajoli, com mais rigor, ainda, a universalidade:

São "direitos fundamentais" todos aqueles direitos que dizem respeito universalmente a "todos" os seres humanos enquanto dotados do status de pessoa, ou de cidadão ou de pessoa capaz de agir. Compreendo por "direito subjetivo" qualquer expectativa positiva (a prestação) ou negativa (a não lesão) vinculada a um sujeito por uma norma jurídica, e por status a condição de um sujeito prevista também esta por uma norma jurídica positiva qual pressuposto da sua idoneidade a ser titular de situações jurídicas e/ou autor dos atos que estão em exercício (FERRAJOLI, 2011, p. 9).

A própria existência do Estado, agente conformador das regras atinentes aos direitos fundamentais, está intimamente relacionada ao ser humano como 
destinatário das normas essenciais, por traduzirem direitos inatos ao cidadão assim considerado pela Constituição Federal de 1988, ao que bem leciona Ingo Wolfgang Sarlet:

Ao consagrar a dignidade da pessoa humana como um dos fundamentos do Estado Democrático (e social) de Direito (art. $1^{\circ}, \mathrm{II}$ ), a CF de 1988, além de ter tomado uma decisão fundamental a respeito do sentido, da finalidade $\mathrm{e}$ da justificação do próprio Estado e do exercício do poder estatal, reconheceu categoricamente que o Estado existe em função da pessoa humana, e não o contrário (SARLET, 2014, apud BLECKMANN, 1997, p. 539).

Já Vidal Serrano Nunes Júnior e Luiz Alberto David Araújo, quando abordam o tema da dignidade da pessoa humana, unem o conceito de dignidade ao conteúdo dos direitos fundamentais e, tal relação, opera em benefício de uma conceituação ampla dos direitos fundamentais:

Existe um valor genérico que permeia a noção de Direitos Fundamentais, qual seja a proteção da dignidade humana em todas as suas dimensões e essa proteção exatamente por abordar as diversas dimensões ou faces da dignidade humana, pode ser segmentada segundo os valores específicos que venham a contemplar (ARAÚJO; NUNES JÚNIOR, 2013, p. 155).

Nas lições de Pietro de Jesús Lora Alarcón, encontra-se a teoria dos três graus do ser e a definição dos patamares existenciais dos seres. Dessa abordagem se faz possível identificar quem é o destinatário das normas dos direitos fundamentais, uma vez identificado o destinatário da proteção da dignidade:

Nessa teoria, a coisa, o indivíduo e a pessoa, são considerados patamares existenciais, sendo que, a primeira é o ser sem unidade, pois se uma coisa quebra nada morre nela. O quebrar coisas nos dá coisas. Porém, ao tomarse contato com o biológico nos deparamos com os indivíduos. E, dentre os indivíduos distinguimos os das espécies não humanas, mas que apresentam potência vital, e o indivíduo da espécie humana. Este último é algo a mais ou representa algo a mais que um indivíduo, pois é uma pessoa, uma substância individual de natureza racional. Assim, tão somente do indivíduo da espécie humana, transformador consciente da realidade, com plena percepção do seu tempo, é dizer, das noções de passado, presente e futuro, pode-se cobrar responsabilidade, posto que é o único que converte natureza em cultura, distinguindo dentre o bom e o ruim, o aceitável e o condenável, o razoável e o absurdo. Nesse sentido, o significado da dignidade expressa algo que eleva, que realiza, que qualifica, e que, portanto,

Em que pese as definições apontadas, não obstante, ainda, a identificação do núcleo protetivo de tais direitos - é dizer da dignidade humana -, não há no 
direito ou nas ciências que o estudam, uma conceituação precisa que envolva todos os elementos caracterizadores de um direito fundamental por definição. Por essa razão, os já citados Luiz Alberto David Araújo e Vidal Serrano Nunes Júnior (2013, p. 153), propõem a adoção de um critério uniforme:

Os Direitos Fundamentais constituem uma categoria jurídica, constitucionalmente erigida e vocacionada à proteção da dignidade humana em todas as dimensões. Destarte, possuem natureza poliédrica, prestandose ao resguardo do ser humano na sua liberdade (direitos e garantias individuais), nas suas necessidades (direitos econômicos, sociais e culturais) e na sua preservação (direitos à fraternidade e à solidariedade) (SARLET, 2012, p. 27).

Dimitri Dimoulis e Leonardo Martins, ensinam que os direitos fundamentais "são direitos público-subjetivos de pessoas (físicas ou jurídicas), contidos em dispositivos constitucionais e, portanto, que encerram caráter normativo supremo dentro do Estado" (DIMOULIS; MARTINS, 2014, p. 41).

Assim, de se verificar que a localização de um direito fundamental no corpo da constituição, não se dá somente em seu aspecto forma de positivação em um rol, como se vê no artigo $5^{\circ}$ da Constituição Federal brasileira de 1988 . Sob o aspecto material, a saber, da análise de seu conteúdo, é que se identifica a fundamentalidade de um direito, da mesma forma, como ensina Walter Claudius Rothenburg:

Certos direitos são fundamentais porque constituem a base do ordenamento jurídico, tanto em sentido axiológico - pois representam os valores mais importantes - quanto em sentido lógico - pois a compreensão do conjunto de normas jurídicas orienta-se por eles. Pode-se, assim, falar na originalidade dos direitos fundamentais, para dizer que são os primeiros a se levar em conta. A fundamentalidade revela-se pelo conteúdo dos direitos fundamentais (o que é dito: a referência aos valores essenciais do ser humano em sociedade e a preocupação com a promoção da dignidade) (ROTHENBURG, 2014, p. 41). (grifo nosso)

Há em toda a análise sobre os direitos fundamentais, uma diferenciação terminológica a ser ao menos esclarecida, a saber, a diferença entre direitos humanos e direitos fundamentais. André de Carvalho Ramos traz a esfera de positivação como a principal diferença, porém, aponta a identidade entre ambos quanto ao objeto de proteção: 
A união de termos mostra que a diferenciação entre direitos humanos, representando os direitos reconhecidos pelo Direito Internacional dos Direitos Humanos, e os 'direitos fundamentais', representando os direitos positivados nas Constituições e leis internas, perde a importância, ainda mais na ocorrência de um processo de aproximação e mútua relação entre o Direito Internacional e o Direito interno na temática dos direitos humanos. [...] Os direitos humanos consistem em um conjunto de direitos considerado indispensável para uma vida humana pautada na liberdade, igualdade e dignidade. Os direitos humanos são os direitos essenciais e indispensáveis à vida digna (RAMOS, 2014, p. 27 e 51).

Por tal característica, ou seja, a positivação em sede de regra constitucional dos direitos essenciais à vida, é que o nível de proteção de tais direitos atinge o grau mais alto do ordenamento jurídico de um Estado Democrático. Por essa razão, ainda, não se deve imprimir rotina à alteração do texto máximo normativo, notadamente no que concerne à fundamentalidade de um direito como cláusula de intangibilidade, a fim de que não se retire do cidadão o que o direito convencionou denominar de sentimento constitucional. Sentimento constitucional, nada mais sendo do que a credibilidade e a adesão de um povo à densidade normativa do texto constitucional, conforme adverte Raul Machado Horta:

\begin{abstract}
O acatamento à Constituição, para assegurar sua permanência, não se resolve exclusivamente no mundo das normas jurídicas, que modela e conduz à supremacia da Constituição. $O$ acatamento à Constituição ultrapassa a imperatividade jurídica de seu comando supremo. Decorre, também, da adesão à Constituição, que se espraia na alma coletiva da Nação, gerando formas difusas de obediência constitucional (...). A reforma constitucional exprime o rompimento do compromisso que mantém o equilíbrio entre os grupos sociais, a Sociedade e o Estado. O segredo da estabilidade da Constituição Norte-Americana, das Constituições monárquicas da Suécia, Noruega, Dinamarca, Bélgica, Luxemburgo e Holanda decorre da raridade de emendas constitucionais. As modificações infrequentes preservam a validez da Constituição e reforçam o seu prestígio na alma do povo (HORTA, 2010, p. 71-72).
\end{abstract}

Assim, ainda sobre a alteração frequente ao texto constitucional, como um instrumento de resposta imediatista - sem a devida reflexão, sem o sopesamento e diferenciação entre o que cem a ser desejo social imediato configurado pela opinião popularizada e anseio social de um povo - do legislador aos problemas sociais, constata Marcelo Neves, a produção da chamada legislação simbólica, sem eficácia social e ensejadora, por consequência, dessa falta de sentimento constitucional:

Os termos "simbólico", "símbolo", "simbolismo", etc., são utilizados nas diversas áreas de produção cultural, frequentemente sem que haja uma predefinição. A isso está subjacente a suposição de que se trata de 
expressões de significado evidente, unívoco, partilhado "universalmente" pelos seus utentes, quando em verdade, nem sempre se está usando a mesma categoria. Ao contrário, estamos diante de um dos mais ambíguos termos da semântica social e cultural, cuja utilização consistente pressupõe, portanto, uma prévia delimitação do seu significado, principalmente para que não se caia em falácias de ambiguidade (NEVES, 2007, p. 5).

De concluir, como se verá a seguir, que os direitos relacionados ao reconhecimento da pessoa idosa como beneficiária da proteção da dignidade humana e, sobretudo, a caraterização de um direito fundamental a ela reconhecido, garantindo-Ihe autonomia e o livre arbítrio para desenhar seu modo de vida (SARLET, 2012, p. 126).

\section{OS DIREITOS DA PESSOA IDOSA COMO REVOLUÇÃO POR DIREITOS}

Abordar a temática dos idosos é abordar dois extremos de distância abissal: de um lado se tem a exata consciência de que nessa época da vida as reflexões encontram-se cada vez melhores, fruto de toda experiência acumulada ao longo da caminhada antecedente, situação que pode ser exemplificada, in terrae brasilis, por boa parte daqueles que ocupam assento em nossa Suprema Corte.

Na outra ponta, os novos desvalidos sociais, abandonados pelo Estado, pela sociedade, pela família, (sobre)vivendo de forma trôpega, com o último fôlego que resta, numa busca pela mantença da dignidade que, quiçá, já Ihe reluziu algum dia.

Não se pode deixar de registrar, nesse contexto, aquilo que Steven Pinker denominou de Revolução de Direitos, a qual consiste, basicamente, no resultado do movimento levado a efeito para conter e criminalizar situações de violência, representado por diversas e contínuas campanhas em prol dos direitos civis, das minorias (PINKER, 2013):

As tendências têm um certo número de coisas em comum. Em cada caso elas tiveram de nadar contra poderosas correntes da natureza humana. Estas incluem a desumanização e a demonização dos de fora do grupo; a rapacidade sexual dos homens e seus sentimentos para com as mulheres; manifestações do conflito pais-filhos tais como o infanticídio e os castigos físicos; a mortalização do repúdio sexual na homofobia; e nossa fome de carne, nosso espírito de caçador e os limites da empatia baseada na semelhança, na reciprocidade e no carisma. [...] Na medida em que a violência é imoral, as Revoluções por Direitos mostram que um modo de vida moral com frequência requer uma decisiva rejeição do instinto, da cultura, da religião e da prática usuais. Em seu lugar, está uma ética que se inspira na empatia e na razão e se embasa na linguagem dos 
direitos. Forçamo-nos a nos colocar no lugar de outros seres capazes de sentir, a considerar seus interesses, a partir do interesse em não ser machucado ou morto, e a ignorar superficialidades que podem atrair nossa atenção, como raça, etnia, gênero, idade, orientação sexual e, até certo ponto, espécie (PINKER, 2013, p. 641-642). (grifo nosso)

\title{
A luta pelo reconhecimento de direitos a determinados grupos
} representantes de uma minoria vulnerável é, por assim dizer, uma Revolução por Direitos, como segue em seus ensinamentos, Pinker:

\begin{abstract}
Essa conclusão é, naturalmente, a visão moral do iluminismo, e dos componentes do humanismo e do liberalismo que cresceram fora dele. As Revoluções por Direitos são revoluções liberais. Cada uma delas foi associada a movimentos liberais e cada uma delas distribui-se ao longo de uma gradação que vai, mais ou menos, da Europa Ocidental para os "estados azuis" dos Estados Unidos, os "estados vermelhos", as democracias da América Latina e Ásia [...]. Durante as Revoluções por Direitos, redes de reciprocidade e intercâmbio se expandiram com a mudança de uma economia baseada em bens para outra baseada na informação. As mulheres tornaram-se menos escravizadas pelas tarefas domésticas e as instituições passaram a procurar talentos em um leque mais amplo de capital humano, e não apenas no suprimento local do velho clube dos sempre (PINKER, 2013, p. 643). (grifo nosso)
\end{abstract}

O contingente social formado pelos idosos também fez e faz parte dessa Revolução de Direitos pois, não obstante a necessidade de efetivação, não se pode olvidar da existência de uma gama protetiva que lhe é específica, a começar pelo Pacto Social de 1988, destacando-se as matrizes basilares positivadas nos artigos 203, V, e, 230, $§ 1 .^{\circ}$, a saber:

Art. 203. A assistência social será prestada a quem dela necessitar, independentemente de contribuição à seguridade social, e tem por objetivos:

Omissis.

V - a garantia de um salário mínimo de benefício mensal à pessoa portadora de deficiência e ao idoso que comprovem não possuir meios de prover à própria manutenção ou de tê-la provida por sua família, conforme dispuser a lei.

[...]

Art. 230. A família, a sociedade e o Estado têm o dever de amparar as pessoas idosas, assegurando sua participação na comunidade, defendendo sua dignidade e bem-estar e garantindo-lhes o direito à vida.

\$1 $1^{\circ}$ Os programas de amparo aos idosos serão executados preferencialmente em seus lares (BRASIL, 1988).

Do mandamento constitucional foram se espraiando outros direitos afetos e condizentes com a peculiar condição em que encontram os idosos, como a 
prioridade na tramitação de processos instituída no Código de Processo Civil ao multidisciplinar e difuso Estatuto do Idoso (Lei n. ${ }^{\circ} 10.741 / 2003$ ) que representou um significativo e qualitativo salto protetivo sobre o tema. Já se passaram aproximadamente 15 anos da aprovação do Estatuto e o que se percebe é uma contínua necessidade aprimoramento, burilamento, e, principalmente, efetividade em muitos de seus campos, voltando-se a uma das questões introduzidas no início deste tópico: os idosos formam o novo grupo de desvalidos sociais.

As teorias contratualistas que explicam o Contrato Social - as relações entre o Estado e os indivíduos -, por certo, buscam definir um patamar conceitual de justiça como integrante desse contrato. Mas algumas questões ainda não foram esclarecidas: a quem se dirigiria a materialização de justiça nessa relação contratual? A todos os seres humanos em um claro prestígio à igualdade?

Quando Immanuel Kant, Thomas Hobbes, Rousseau, John Locke, Hugo Grotius, David Hume narraram, cada um a sua maneira, as perspectivas dos Contrato Social, ou no momento em que enunciou sua da teoria da justiça por equidade, John Rawls, não se vislumbrava situações sociais excludentes que hoje a busca pela efetivação dos direitos humanos enfrenta.

Tal constatação se faz possível tanto pela evolução do ser humano que vive em sociedade, quanto pela reconfiguração dos anseios sociais. Reconfiguração essa, não consagrada pelo que se convencionou preconizar diante da previsão de uma sociedade única, como objeto do Contrato Social em sua origem, assim em seus antigos traços, porém, ainda em vigor nos dias de hoje. Não se tolera mais um Contrato Social, cujas cláusulas, por assim dizer, não guarnecem os princípios constitucionais atuais, da mesma forma as conquistas sociais traduzidas na positivação de direitos fundamentais antes distantes do ponto de chagada e os anseios por justiça hoje desenvolvidos.

Não se vislumbra mais efetivação de justiça, ao que Rawls denominou de justiça por equidade, ante um Contrato Social incompleto. Sabe-se que por justiça, entende-se a máxima de "dar a cada um o que de direito". Em que pese, os teóricos do contrato social não incluíram - e essa é a melhor palavra que define - no sentido de "cada um", aqueles que deveriam ser incluídos. Nesse sentido, Martha Craven Nussbaum, em precisa ponderação acerca do que se expôs: 
Em um mundo cada vez mais interdependente, precisamos considerar as questões de justiça levantadas pelas desigualdades entre nações ricas e pobres, que afetam as chances de vida de seus cidadãos. O modelo do contrato é tipicamente usado para construir uma única sociedade, imaginada como autossuficiente, e não como interdependente com alguma outra. Tanto Kant quanto Rawls de fato reconhecem a importância de confrontar questões de justiça entre as nações (NUSSBAUM, 2013, p. 2324).

Nesse sentido, no universo de origem das teorias explicativas do Contrato Social, há de se lembrar e concluir que os indivíduos sobre os quais recaíam as regras de tal contrato eram seres humanos iguais em capacidade, excluindo-se da tratativa social, as crianças e as pessoas idosas (NUSSBAUM, 2013, p. 18).

5 CONCLUSÃO

Os abusos não se limitam a violência física e ao abandono afetivo-familiar!

Verifica-se, em larga escala, o flagelo impingido aos idosos pelos planos de saúde, seja por meio de cobranças exorbitantes, seja pela imposição de carências diferenciadas, seja pelas mais diversas e absurdas negativas de cobertura médicohospitalar, tornando-se clientes contumazes do Poder Judiciário, sem que isso os intimide ou mude seu comportamento.

Ao que parece, a problemática atinente a efetivação dos direitos atinentes ao grupamento formado por nossos idosos perpassa muitos mais por uma mudança de atitude da sociedade como um todo do que na hiperinflação legislativa, muitas vezes mais com um caráter álibi ou salvo-conduto do que de resolutório propriamente dito.

Assim, sem sombra de dúvidas, se coloca como de importância primaz o fornecimento de educação de qualidade desde crianças e adolescentes, de modo que, com o conhecimento recebido nos bancos escolares, tenham condições de apresentar, no futuro, respeito pelo próximo, além de fortalecer os laços dentro da família a que pertencem.

Entender que o ciclo da vida é cronologicamente crescente e que todos passarão por essa nobre condição e também precisarão dos mesmos cuidados e proteções: enfim, o jovem de hoje é o idoso de amanhã!

A necessidade de empreender políticas públicas, a fim de garantir a efetividade dos dispositivos legais que amparam a pessoa idosa, é premente. 
Pensar a pessoa idosa como pertencente a uma minoria vulnerável é, antes de tudo, necessário, já que somente assim a inclusão será parte da Revolução de Direitos justa para o reconhecimento de dignidade e da identidade das pessoas que compõem referido grupo. Enfrentar tal situação social excludente é um desafio de revisão, portanto, das cláusulas do Contrato Social.

\section{REFERÊNCIAS}

BRAGA, Pérola Melissa Vianna. Curso de direito do idoso. São Paulo: Atlas, 2011. BRASIL, Lei n. ${ }^{\circ} 10.173$, de 09 de janeiro de 2011. Dispõe sobre o Estatuto do Idoso e dá outras providências. Diário Oficial União, 03 out 2001.

COMPARATO, Fábio Konder. A afirmação histórica dos direitos humanos. 9. ed. São Paulo: Saraiva, 2015.

DIMOULIS, Dimitri; MARTINS, Leonardo. Teoria Geral dos Direitos Fundamentais. 5. ed. São Paulo: Atlas, 2014.

FERRAJOLI, Luigi. Por uma teoria dos direitos e dos bens fundamentais. Tradução de Alexandre Salim, Alfredo Copetti Neto, Daniela Cademartori, Hermes Zaneti Júnior e Sérgio Cademartori. Porto Alegre: Livraria do Advogado, 2011.

FREITAS JÚNIOR, Roberto Mendes de. Direitos e garantias do idoso. Doutrina, jurisprudência e legislação. 2. São Paulo: Atlas, 2011.

HORTA, Raul Machado. Direito Constitucional. 5. ed. Belo Horizonte: Del Rey, 2010.

LEITE, Flávia Piva Almeida. Cidades acessíveis. São Paulo: SRS, 2012.

MARTINEZ, Wladimir Novaes. Comentários ao Estatuto do Idoso. 2. ed. São Paulo: LTr, 2005.

NEVES, Marcelo. A constitucionalização simbólica. 2. ed. São Paulo: VWF Martins Fontes, 2007.

NUSSBAUM, Martha Craven. Fronteiras da justiça: deficiência, nacionalidade, pertencimento à espécie. Tradução de Susana de Castro. São Paulo: Editora WMF Martins Fontes, 2013.

RAMOS, André de Carvalho. Curso de Direitos Humanos. São Paulo: Saraiva, 2014. 
RAMOS, Paulo Roberto Barbosa. Curso de direito do idoso. São Paulo: Saraiva, 2014.

ROTHENBURG, Walter Claudius. Direitos Fundamentais. In: TAVARES, André Ramos; FRANCISCO, José Carlos (Coord). Coleção Carreiras Federais. Rio de Janeiro: Forense, São Paulo: Método, 2014.

SARLET, Ingo Wolfgang. A eficácia dos Direitos Fundamentais: uma teoria geral dos direitos fundamentais na perspectiva constitucional. 11. ed. Porto Alegre: Livraria do Advogado Editora, 2012.

SARLET, Ingo Wolfgang. Dignidade da pessoa humana. In: CANOTILHO, J.J. Gomes (Org.) [et. al]. Comentários à Constituição do Brasil. São Paulo: Saraiva, 2014, apud Albert BLECKMANN, 1997.

ZAGREBELSKY, Gustavo. El derecho dúctil: ley, derechos, justicia. Madri: Editorial Trotta, 2011. 